\title{
Epidemiology: Past, Present, and Future Impacts on Understanding Disease Dynamics and Improving Plant Disease Management-A Summary of Focus Issue Articles
}

\author{
P. S. Ojiambo, ${ }^{\dagger}$ J. Yuen, F. van den Bosch, and L. V. Madden \\ 2017 Focus Issue Senior Editors
}

\begin{abstract}
First author: Center for Integrated Fungal Research, Department of Entomology and Plant Pathology, North Carolina State University, Raleigh 27695; second author: Department of Forest Mycology and Plant Pathology, Swedish University of Agricultural Sciences, Uppsala, Sweden; third author: Rothamsted Research, West Common, Harpenden, AL5 2JQ, U.K.; and fourth author: Department of Plant Pathology, The Ohio State University, Ohio Agricultural Research and Development Center, Wooster 44691.
\end{abstract}

Epidemiology has made significant contributions to plant pathology by elucidating the general principles underlying the development of disease epidemics. This has resulted in a greatly improved theoretical and empirical understanding of the dynamics of disease epidemics in time and space, predictions of disease outbreaks or the need for disease control in real-time basis, and tactical and strategic solutions to disease problems. Availability of high-resolution experimental data at multiple temporal and spatial scales has now provided a platform to test and validate theories on the spread of diseases at a wide range of spatial scales ranging from the local to the landscape level. Relatively new approaches in plant disease epidemiology, ranging from network to information theory, coupled with the availability of large-scale datasets and the rapid development of computer technology, are leading to revolutionary thinking about epidemics that can result in considerable improvement of strategic and tactical decision making in the control and management of plant diseases. Methods that were previously restricted to topics such as population biology or evolution are now being employed in epidemiology to enable a better understanding of the forces that drive the development of plant disease epidemics in space and time. This Focus Issue of Phytopathology features research articles that address broad themes in epidemiology including social and political consequences of disease epidemics, decision theory and support, pathogen dispersal and disease spread, disease assessment and pathogen biology and disease resistance. It is important to emphasize that these articles are just a sample of the types of research projects that are relevant to epidemiology. Below, we provide a succinct summary of the articles that are published in this Focus Issue.

\section{SOCIAL AND POLITICAL CONSEQUENCES OF DISEASE EPIDEMICS}

Historically, epidemics of plant diseases have had significant implications on the social and even political welfare of mankind. Outbreaks of epidemics of new and re-emerging plant diseases still continue to challenge and shape society in the 21 st century. Plant disease epidemics influence mobilization of resources to combat outbreaks and social processes by which society becomes stigmatized during disease outbreaks and the ensuing unrest. Using examples of specific disease epidemics, Zadoks (2017) provides an in-depth review of the social and political impacts of some epidemics of historical importance. The failure of the French grain crop resulted

${ }^{\dagger}$ Corresponding author: P. S. Ojiambo; E-mail: pojiamb@ncsu.edu

(C) 2017 The American Phytopathological Society in people eating ergot-infested immature rye and although the French Revolution of 1789 was not due to ergot, the disease politically contributed to the revolution. Wheat stem rust directly contributed to the great famine of 1932 in the Soviet Union that led to the death of about 5 million people, most of whom were in the countryside. The potato late blight epidemic in England, Ireland and Germany in 1846 led to migration of a million people from Europe to the Americas. The ensuing poverty and hunger resulted in a revolution in France a couple of years later and uprisings in several capital cities in Europe. The genesis of important agricultural institutions such as the United Nations Food and Agriculture Organization and the Fungal Biodiversity Institute in the Netherlands can be traced back to the outbreaks of disease epidemics. This perspective highlights how epidemics can impact society and emphasizes the continued need to understand disease dynamics and apply principles derived thereof to improve plant disease management.

\section{PATHOGEN DISPERSAL AND DISEASE SPREAD}

Dispersal of pathogens is key to development of plant disease epidemics. Considerable efforts in the past have been directed at understanding physical aspects of spore dispersal of plant pathogens. Theoretical and physical information on spore dispersal has been applied to specific host systems to facilitate prediction of transport over short and long distances. Efforts have also been made to collect field data to validate findings from theoretical predictions of velocity of spread over distance. Recent efforts have focused on the physical and biological mechanisms of dispersal at scales ranging from the microscopic to the continental, and how such information can be applied to understand development of epidemics and manage plant diseases.

Meyer et al. (2017) apply a Lagrangian spore dispersal model to the incursion of race TKTTF of wheat stem rust to determine likely aerial origins of spores on regional and continental scales. Consistent with the available data from field sampling and phylogenetic analysis, their simulations point to Yemen as the most likely origin of TKTTF race but also point to Middle East and the East African Rift-Valley as other possible sources. A semi-operational forecast model pipeline has since been developed for rust dispersal from field sites of observed rust appearance in Ethiopia and forecast outputs are used to inform and target control or scouting activities in areas of highest risk of spore incursion. Wen et al. (2017) apply machine-learning models to spore dispersal and identify distance from source, humidity, temperature, wind direction, and wind speed as the most important variables influencing short-distance aerial dispersal of urediniospores of Phakopsora pachyrhizi. Such information is useful in understanding long-distance dispersal of spores, for aerobiological modeling, and for forecasting disease outbreaks. 
Spatial pattern is a fundamental property of disease dynamics since it reflects, in part, the environmental forces acting on pathogen dispersal and subsequent disease establishment and spread. Thus, knowledge of spatial patterns can improve understanding of dispersal and facilitate design of improved disease management strategies. Gigot et al. (2017) characterized and quantified spatial patterns of strawberry angular leaf spot at multiple scales and showed that recurrent crop husbandry operations along agronomic rows play a significant role in disease spread. Accounting for these recurrent agronomic operations when designing management strategies can greatly improve disease control. Geospatial techniques were applied by Szyniszewska et al. (2017) to mechanistically define, for the first time for plant virus epidemics, the front of the cassava mosaic disease pandemic in Tanzania. Their study reveals that the pandemic front is relatively complex and may not always be easily described with a smooth line running through contiguous areas. Their approaches could be useful in monitoring patterns of development of CMD epidemics in other parts of Africa. Hilker et al. (2017) used mathematical modeling to analyze the spread of the viruses causing the deadly maize lethal necrosis (MLN) in sub-Saharan Africa to predict how management influences disease prevalence and crop performance. Large-scale farmers can achieve good control of MLN by combining clean seed and insect control, while small-scale farmers with limited resources must rely on crop rotation and roguing to achieve more limited disease control. In addition, the authors show that exogenous sources of infection can impede MLN control unless disease management is synchronized over large areas.

\section{DECISION THEORY AND SUPPORT SYSTEMS IN DISEASE MANAGEMENT}

Epidemiologists strive to understand how environmental and biological factors interact to drive disease outbreaks and subsequent crop loss. Once these factors are identified and quantified, they are typically combined using risk algorithms to make predictions to inform the need for crop protection measures. Formal Bayesian theory is fundamental in the construction and evaluation of these prediction systems. In this context, measures defined conditionally based on the status of the disease have been the standard approach in evaluating disease prediction systems. Hughes and Burnett (2017) provide an analytical perspective on the evaluation of probabilistic disease forecasts. The authors indicate that while metrics defined conditionally based on the predictive value of the disease forecast are less frequently reported, they are important in evaluating such forecasts. In this regard, the authors discuss the application of scoring rules in making management decisions and conclude that the decomposition of scoring rules into interpretable components is an advantageous feature of their application in disease forecasting. In general, the use of scoring rules is a useful alternative approach for evaluating the accuracy of probabilistic disease forecasts in plant pathology.

\section{DISEASE ESTIMATION AND RISK ASSESSMENT}

Accurate quantification of disease is fundamental in plant pathology since it allows epidemiologists to reliably assess crop loss and determine the effectiveness of disease management practices. Standard area diagrams (SADs) have been used for visual assessment of disease severity and have increasingly been recognized as an aid to obtaining more accurate data. Del Ponte et al. (2017) reviewed research on SADs through a quantitative synthesis of the literature and discussed useful tools to improve accuracy and reliability of disease severity estimates. Availability of algorithms in statistical software for performing concordance analysis and bootstrapping tests likely boosted the recent increased use of SADs in plant pathology since it allowed for improved validation efforts. Their synthesis provides a knowledge-base for increased understanding of SAD technology, and aspects of this technology that may improve the accuracy of disease estimation.
Assessing the risk of disease outbreak in agricultural systems is critical in designing and implementing effective disease control measures. In plant disease epidemiology, risk assessment typically involves identifying and characterizing the source of the risk and then estimating the likelihood of an undesirable event occurring at a given location and time. Seed degeneration due to build-up of pathogens in vegetatively propagated materials is of major concern in developing countries. Combing environmental factors and disease management practices at different geographical scales could be useful in developing an integrated seed health strategy to mitigate seed degeneration. Thomas-Sharma et al. (2017) present a risk assessment framework to evaluate the relative performance of individual and combined components of an integrated seed health strategy. The authors show that on-farm seed selection can be as effective as certified seed if the rate of success in selecting healthy plants for seed production is high. In addition, combining management components can be synergistic and keep seed degeneration below a threshold of rapid disease increase when individual management approaches are ineffective.

Epidemiological analyses can address fairly complex and diverse systems but standard statistical approaches are not always suitable for analyzing data generated from such systems. Scenario analysis (also known as morphological analysis) makes it possible to analyze complex and multidimensional problems for developing future scenarios and allows very complex problem areas to be disassembled into different components, which then can be analyzed separately and combined into different scenarios. Savary et al. (2017) designed a framework for scenario analysis and applied it to global wheat health through 2050. Their analyses which considered climate change and climate variability, nitrogen fertilizer use, tillage, crop rotation, pesticide use, and the deployment of host resistance suggests an increase in the risk of disease caused by biotrophic and necrotrophic pathogens. This work accentuates the value of developing and applying scenario analyses in epidemiology in relation to global change to prioritize important research areas in wheat crop health.

Appropriate implementation of phytosanitary thresholds is critical for seed systems to remain resilient and adaptable to the introduction of new pathogens. Seed growers and producers have competing objectives when setting these thresholds, and Choudhury et al. (2017) illustrate the general conditions under which these partially competing objectives can be satisfied. Using downy mildew of spinach, the authors show that a seed lot threshold of 0.23 oospores per seed could reduce the overall number of oospores entering the production system by $90 \%$, while removing $8 \%$ of seed lots destined for distribution. The authors also discuss how their approach can be applied and generalized across different seed systems. The risk of epidemics from seedborne pathogens can also be determined based on the structure of seed networks. Using potato production in Ecuador as a case study, Buddenhagen et al. (2017) apply scenario analysis to study potential epidemics in seed transaction networks, and the role that particular network nodes play in sampling and mitigating epidemics caused by seedborne pathogens. Their results identified key control points that influence the success of seed systems and observed that investment in nodes to improve pest control and disease outbreaks can lead to improvements in seed systems.

\section{PATHOGEN BIOLOGY, ENVIRONMENT, AND DISEASE RESISTANCE}

Integration of epidemiology, environmental science, and population genetics within the context of population biology continues to play an essential role in addressing management of plant diseases. Cohen et al. (2017) provide an elaborate review on the epidemiology of basil downy caused by the oomycete Peronospora belbahrii. The pathogen is sensitive to high temperature, and disease progress is significantly reduced when net houses are covered with polythene sheets for about $2 \mathrm{~h}$ on consecutive days. This decrease in development is, however, due to an indirect effect of high temperature on the host rather than a deleterious effect on the pathogen. Nocturnal fanning preventing dew deposition on leaf 
surfaces strongly limits infection and sporulation and prevents epidemics. Availability of nutrients to fungal pathogens due to fertilization application can modulate the severity of epidemics either at the leaf or canopy level. Précigout et al. (2017) use the theoretical framework of physiologically structured population models to determine how disease epidemics and plant pathogens evolve in response to changes in fertilization level. They predict that that high resource levels would allow more strains with different latent periods to coexist in the field than low resource levels. Reducing fertilization will change the aggressiveness profiles of different biotrophic pathogen species in the field.

Some standard statistical methods used to compare population genetics of plant pathogens rely on assumptions about the biology of microorganisms that may not hold for plant pathogens. Soubeyrand et al. (2017) describe a statistical method for small samples and sparse data that does not require a priori biological knowledge for the system of interest when testing the similarity of genetic compositions of two pathogen populations. The authors illustrate the power of the Generalized Monte Carlo plug-in test with calibration (GMCPIC) that is implemented in $\mathrm{R}$ using the GMCPIC R package. Using a simulation study, the authors provide guidelines on how to apply the GMCPIC test depending on the sample sizes of the test organism.

Host disease resistance is one of the most sustainable approaches for management of plant diseases, and coordination of structured crop breeding networks when deploying resistance genes can decrease the likelihood that pathogens will overcome resistance. Garrett et al. (2017) evaluate the general structure of crop breeding networks for cassava, potato, rice, and wheat. The authors apply theory from complex adaptive systems to develop a policy framework for evaluating crop breeding networks for the spread and deployment of resistance genes. Their findings indicate that these breeding networks must adapt to global change in climate and land use, the emergence of new diseases, and disruptive breeding technologies.

\section{LITERATURE CITED}

Buddenhagen, C. E., Hernandez Nopsa, J. F., Andersen, K. F., Andrade-Piedra, J., Forbes, G. A., Kromann, P., Thomas-Sharma, S., Useche, P., and Garrett, K. A. 2017. Epidemic network analysis for mitigation of invasive pathogens in seed systems: Potato in Ecuador. Phytopathology 107:1209-1218.

Choudhury, R. A., Garrett, K. A., Klosterman, S. J., Subbarao, K. V., and McRoberts, N. 2017. A framework for optimizing phytosanitary thresholds in seed systems. Phytopathology 107:1219-1228.
Cohen, Y., Naim, Y. B., Falach, L., and Rubin, A. V. 2017. Epidemiology of basil downy mildew. Phytopathology 107:1149-1160.

Del Ponte, E. M., Pethybridge, S. J., Bock, C. H., Michereff, S. J., Machado, F. J., and Spolti, P. 2017. Standard area diagrams for aiding severity estimation: Scientometrics, pathosystems and methodological trends in the last 25 years. Phytopathology 107:1161-1174.

Garrett, K. A., Andersen, K. F., Asche, F., Bowden, R. L., Forbes, G. A., Kulakow, P. A., and Zhou, B. 2017. Resistance genes in global crop breeding networks. Phytopathology 107:1268-1278.

Gigot, C., Turechek, W., and McRoberts, N. 2017. Analysis of the spatial pattern of strawberry angular leaf spot in California nursery production. Phytopathology 107:1243-1255.

Hilker, F. M., Allen, L. J. S., Bokil, V. A., Briggs, C. J., Feng, Z., Garrett, K. A., Gross, L. J., Hamelin, F. M., Jeger, M. J., Manore, C. A., Power, A. G., Redinbaugh, M. G., Rúa, M. A., and Cunniffe, N. J. 2017. Modelling virus coinfection to inform management of maize lethal necrosis in Kenya. Phytopathology 107:1095-1108.

Hughes, G., and Burnett, F. J. 2017. Evaluation of probabilistic disease forecasts. Phytopathology 107:1136-1143.

Meyer, M., Burgin, L., Hort, M. C., Hodson, D. P., and Gilligan, C. A. 2017. Large-scale atmospheric dispersal simulations identify likely airborne incursion routes of wheat stem rust into Ethiopia. Phytopathology 107:1175-1186.

Précigout, P. A., Claessen, D., and Robert, C. 2017. Crop fertilization impacts epidemics and optimal latent period of biotrophic fungal pathogens. Phytopathology 107:1256-1267.

Savary, S., Djurle, A., Yuen, J., Ficke, A., Rossi, V., Esker, P. D., Fernandes, J. M. C., Del Ponte, E. M., Kumar, J., Madden, L. V., Paul, P., McRoberts, N., Singh, P. K., Huber, L., de Vallavielle, C. P., Saint-Jean, S., and Willocquet, L. 2017. A white paper on global wheat health based on scenario development and analysis. Phytopathology 107:1109-1122.

Soubeyrand, S., Garreta, V., Monteil, C., Suffert, F., Goyeau, H., Berder, J., Moinard, J., Fournier, E., Tharreau, D., Morris, C. E., and Sache, I. 2017. Testing differences between pathogen compositions with small samples and sparse data. Phytopathology 107:1199-1208.

Szyniszewska, A. M., Busungu, C., Boni, S. B., Shirima, R., Bouwmeester, H., and Legg, J. P. 2017. Spatial analysis of temporal changes in the pandemic of severe cassava mosaic disease in Northwestern Tanzania. Phytopathology 107:1229-1242.

Thomas-Sharma, S., Andrade-Piedra, J., Carvajal Yepes, M., Hernandez Nopsa, J. F., Jeger, M. J., Jones, R. A. C., Kromann, P., Legg, J. P., Yuen, J., Forbes, G. A., and Garrett, K. A. 2017. A risk assessment framework for seed degeneration: Informing an integrated seed health strategy for vegetatively propagated crops. Phytopathology 107:1123-1135.

Wen, L. C., Bowen, C. R., and Hartman, G. L. 2017. Prediction of shortdistance aerial movement of Phakopsora pachyrhizi urediniospores using machine learning. Phytopathology 107:1187-1198.

Zadoks, J. C. 2017. On social and political effects of plant pest and disease epidemics. Phytopathology 107:1144-1148. 